\title{
EFFECT OF EDUCATIONAL TRAINING ON NUTRITION AND WEIGHT MANAGEMENT IN ELITE SPANISH GYMNASTS
}

\author{
Andrea Visiedo, 1, A, B, C, D Jillian E. Frideres, 2, A, D Jose M. Palao 3, A, B, C, D \\ ${ }^{1}$ Physical Activity and Sport, University of Murcia, Murcia (Spain) \\ 2 University of Wisconsin-Madison Division of Extension (USA) \\ ${ }^{3}$ Department of Health, Exercise Science and Sport Management, University of Wisconsin-Parkside (USA). \\ A Study Design; ${ }^{\mathrm{B}}$ Data Collection; ${ }^{\mathrm{C}}$ Statistical Analysis; ${ }^{\mathrm{D}}$ Manuscript Preparation; ${ }^{\mathrm{E}}$ Funding \\ Address for correspondence: \\ Andrea Visiedo \\ Facultad de Ciencias del Deporte \\ Universidad de Murcia \\ Calle Argentina, 19, 30720 San Javier, Murcia (Spain) \\ E-mail: andreavismero@gmail.com
}

\begin{abstract}
Ahstract The aim was to study the effect of a formative program about nutrition as well as weight management and its risks in elite gymnasts. The sample was 37 under-18 Spanish athletes from rhythmic and aesthetic gymnastics (national level). The sample was divided into a control group $(n=21)$ and an intervention group $(n=16)$. A quasi-experimental design with a pre-test and post-test was used. The dependent variable was the knowledge of nutrition, weight management, and its risks. The independent variable was the educational program. The program had three 30 -minute sessions which combined talks, videos, and tasks to complete. Descriptive and inferential analyses were done. The educational program was ineffective with regard to increasing the gymnasts' knowledge about nutrition, weight management, and its risks. The gymnasts' knowledge of nutrition and weight management was high before beginning the intervention. Gymnasts and the coach expressed the need for individualized training adapted to each gymnast's needs and for incorporating a follow-up that provides feedback that is applicable in the gymnast's daily life.
\end{abstract}

Key WOrlls aesthetic sport, performance, prevention, knowledge

\section{Introduction}

Performance in aesthetic sports, such as rhythmic gymnastics, is evaluated by the physical appearance of the athlete's executions (Douda, Toubekis, Avloniti, Tokmakidis, 2008; Lazarevic, Petrovic, Ramnjanovic, 2012). This results in athletes and coaches placing great importance on the physical appearance and shape of the athletes (Gomez-Campos, Camargo, Arruda, Cossio Bolaños, 2013; Hergenroeder, Broun, Klish, 1997; Klentrou, Plyley, 2003; Tan, Calitri, Bloodworth, McNamee, 2016). The importance placed on the athletes' physical appearance, the search for perfection in this type of sport, and the physical and psychological changes in adolescence mean that young gymnasts are at risk for health problems related to weight management and disordered eating (Bonci 
et al., 2008; Cupisti, D’Alessandro, Castrogiovanni, Barale, Morelli, 2000; Evans, Rich Holroyd, 2004; Halmi, 2009; Sundgot-Borgen, 1994; Sundgot-Borgen, 1996). The reference image that media and elite athletes provide to young gymnasts is a distortion of the reality in the way that they focus on peak-performance athletes. Therefore, young gymnasts have several models as a reference: from society, models stylized with the help of Photoshop, and from sport, the body that peak-performance athletes have at the pinnacle of their sport life, after years of dedication and training. Among the possible ways of reducing the risks involved in this situation is providing young athletes with information and skills through education (Coppola, Vastola, Scatigna, Fabiani, 2014; Sundgot-Borgen, 1994).

In gymnastics, although athletes' knowledge of nutrition is good, they have been found to have an energy deficit due to the intensity and duration of their training (D'Alessandro et al., 2007; Deutz, Benardot, Martin, Cody, 2000). Some studies have found that elite gymnasts have high carbohydrate intakes and low intakes of lipids, calcium, and proteins (Michopoulou, Avloniti, Kambas, Leontsini, Michalopoulou, 2011; Gomez-Campos et al., 2013; Nordin et al., 2003). Despite insufficiencies, gymnasts have perceived that they had adequate dietary habits (Jonnalagadda, Benardot and Nelson, 1993) and that they had a good dietary distribution throughout the day (Nordin, Harris, Cumming, 2003). During the competitive season, gymnasts change their dietary habits, reaching caloric levels considered inadequate (Michopoulou et al., 2011). In the bibliography, no specific studies have been found about educational training regarding nutrition or weight management. However, several studies have reported their need as well as the higher incidence of disordered eating and eating disorders in gymnastics (Anderson, Petrie, 2012; Sundgot-Borgen, Torstveit, 2004).

There are many aspects that can contribute to the development of unhealthy behaviors related to nutrition and weight management in young athletes. The different stakeholders in these sports must be actively involved in creating environments and resources that promote the athletes' wellbeing. Ideally, the coaches and parents will also be involved in this process. Further, the interventions must provide and reinforce the importance and role of nutrition, healthy reference models, and how athletes should manage their weight and the risks involved in weight management. The aim of this study was to assess the effect of a formative program about nutrition, weight management, and its risks in elite gymnasts.

\section{Material and Methods}

The sample was composed of 37 under-18 gymnasts that participated at least once in a Spanish national Championship of rhythmic gymnastics. The sample was divided into a control group $(n=21)$ and an intervention group $(n=16)$, and convenience sampling based on the training location of the gymnasts was utilized. The characteristics of the sample are described in table 1. The study was approved by the Ethics Committee of the first researcher. Parents and guardians of all participants signed an informed consent before the study began. Participation in the study was voluntary, and all participants were informed about the study.

Table 1. The sample's characteristics (Gymnastics)

\begin{tabular}{lcccccc}
\cline { 2 - 6 } & \multicolumn{2}{c}{ Age $(\mathrm{yr})$} & \multicolumn{2}{c}{ Height $(\mathrm{m})$} & \multicolumn{2}{c}{ Weight $(\mathrm{kg})$} \\
\cline { 2 - 7 } & $\mathrm{M}$ & $\mathrm{SD}$ & $\mathrm{M}$ & $\mathrm{SD}$ & $\mathrm{M}$ & $\mathrm{SD}$ \\
\hline Intervention group $(\mathrm{n}=16)$ & 14.25 & 2.05 & 1.59 & 0.08 & 44.6 & 8.8 \\
Control group $(\mathrm{n}=21)$ & 16.61 & 1.22 & 1.65 & 0.04 & 52.3 & 3.8 \\
\hline
\end{tabular}


A pre-test and a post-test were utilized in this quasi-experimental design. The knowledge of nutrition, weight management, and its risks was the dependent variable, and the educational program was the independent variable. An ad-hoc questionnaire was utilized to measure the athletes' knowledge. Questionnaires and interviews were used to register the coach's and gymnasts' perception. The program consisted of three 30-minute sessions, which combined talks, videos, and tasks to complete.

Manuals about the topic were utilized to design the questionnaire and the training (Bean, 2011; Bonci et al., 2009). The questionnaire evaluated basic nutrition knowledge as well as knowledge of weight management and its risks. The questionnaire consisted of 41 true-false questions (18 about weight management and its risks and 23 about nutrition knowledge). Both the questionnaire and the training were validated by experts (content validity). Experts were asked to evaluate quantitative (on a scale from 1 to 10) and qualitative (open) questions from the questionnaire and the training with regard to: degree of understanding, degree of adequacy, and the need to reduce or include more questions or information. In accordance with Bulger and Housner (2007), questions with values $<7.0$ were eliminated, questions with values $>7.0$ and $<8.0$ were modified, and questions with values $>8.0$ were accepted or accepted with modifications. A test-retest protocol with 11 international-level gymnasts ( $16 \pm 1.16$ years of age) was used to establish the reliability of the questionnaire. The reliability of each item was calculated using the Kappa Index in the SPSS software. The lowest value for any question was 0.609 (Visiedo, Frideres, Palao, 2017).

The goal of the program was to provide the gymnasts with knowledge about nutrition, weight management, and its risks. The sessions were incorporated into the gymnasts' training schedule. Each session consisted of two 15-minute blocks, the first of which was theoretical and the second of which was practical (tasks to complete). The content distribution for the three sessions included basic nutrition knowledge, weight management and eating habits, and weight management risks. One of the researchers directed the sessions. At the start of the intervention, a document with the information provided during the sessions was given to the gymnasts. The questionnaire was completed before the start and four weeks after the intervention program, and the interviews were completed four weeks after the program. Descriptive (average, standard deviation, percentages) and inferential analyses of the results were done using SPSS software. Differences between the pre-test and the post-test were calculated using T-tests for categorical questions and ANOVAs for independent variables for continuous questions. Significance was set at $p<0.05$.

\section{Results}

The educational training was ineffective with regard to increasing the nutrition and weight management knowledge of the intervention group (Tables 2 and 3). Both groups had scores that were higher than $75 \%$ for nutrition knowledge as well as weight management. No significant differences were found between the intervention and control groups in the pre-test or the post-test.

Table 2. Effect of the educational training on nutrition knowledge in gymnasts

\begin{tabular}{lcccccccc} 
& \multicolumn{4}{c}{ Pre-test } & \multicolumn{3}{c}{ Post-test } \\
\cline { 2 - 9 } & \multicolumn{2}{c}{ scale (0 to 23) } & \multicolumn{2}{c}{ percentage } & \multicolumn{2}{c}{ scale (0 to 23) } & \multicolumn{2}{c}{ percentage } \\
\cline { 2 - 9 } & $\mathrm{M}$ & $\mathrm{SD}$ & $\mathrm{M}$ & $\mathrm{SD}$ & $\mathrm{M}$ & $\mathrm{SD}$ & $\mathrm{M}$ & $\mathrm{SD}$ \\
\hline Intervention group & 19.56 & 1.88 & 78.22 & 7.51 & 19.33 & 2.4 & 77.33 & 9.5 \\
Control group & 17.87 & 1.80 & 77.60 & 9.00 & 19.30 & 2.1 & 75.80 & 11.1 \\
\hline
\end{tabular}


Table 3. Effect of the educational training on weight management knowledge in gymnasts

\begin{tabular}{lcccccccc} 
& \multicolumn{4}{c}{ Pre-test } & \multicolumn{3}{c}{ Post-test } \\
\cline { 2 - 9 } & \multicolumn{2}{c}{ scale (0 to 18) } & \multicolumn{2}{c}{ percentage } & \multicolumn{2}{c}{ scale (0 to 18) } & \multicolumn{2}{c}{ percentage } \\
\cline { 2 - 9 } & $\mathrm{M}$ & $\mathrm{SD}$ & $\mathrm{M}$ & $\mathrm{SD}$ & $\mathrm{M}$ & $\mathrm{SD}$ & $\mathrm{M}$ & $\mathrm{SD}$ \\
\hline Intervention group & 15.67 & 1.41 & 87.05 & 7.86 & 16.22 & 1.20 & 90.12 & 6.68 \\
Control group & 14.10 & 5.83 & 78.30 & 6.30 & 14.85 & 5.47 & 82.55 & 8.30 \\
\hline
\end{tabular}

Three ideas were collected about the effect of the educational intervention from the opinions and perceptions of the gymnasts and coach, which were collected from the questionnaires and the interviews: 1) retention and effect of the educational program; 2) level of engagement in the program, and 3) evaluation of the program.

1. Retention and effect of the educational program. Seventy percent of the gymnasts highlight that the educational program helped them to make some changes in their dietary habits or to remind them of information that they already knew. These ideas were expressed in the following way:

It was helpful, a reminder of how to manage the meal schedule and learn more about quantity and proportions" [Gymnast \#8]

It will help me to pay more attention and eat better... [Gymnasts \#5, \#6]

I already had information about this. It was a reminder [Gymnast \#1]

2. Level of engagement of the gymnast. There were differences between the engagement mentioned by the gymnasts and that mentioned by the coach. Sixty percent of the gymnasts said that they were interested in the topic and need to pay more attention to what and how much they eat. The coach commented that the gymnasts were not completely committed or engaged in the process.

I pay attention to my meals and to food proportions [Gymnasts \#1-6]

It was interesting [Gymnasts \#7, \#10, \#12]

[There was] moderate engagement, but we must review the topic often. It was interesting [Coach]

3. Evaluation of the program. Eighty percent of the gymnasts liked the educational intervention. Most of the gymnasts and the coach expressed the need to incorporate more specific, individualized information that is applicable to the gymnasts and their diets in their daily life.

...We should plan each athlete's diet, because we are not the same [Gymnast \#8]

It is necessary to combine the educational training with follow-up in their day-to-day... the information must be individualized for each one [Coach]

\section{Discussion}

The intervention, based on theoretical and practical classes and providing the gymnast with educational material, did not increase the gymnasts' knowledge of nutrition or weight management. There are possible explanations for these results. The gymnasts' knowledge was high to begin with, which is in accordance with other 
studies in the literature, as elite gymnasts have been found to have good knowledge about nutrition (Cupisti et al., 2000; D’Alessandro et al., 2007; Karabudak, Köksal, Ertaş, Küçükerdönmez, 2016). Another possible reason is that the intervention was not long enough and/or specific enough. Most of the gymnasts considered the intervention to be interesting but a reminder of information they already knew. The gymnasts emphasized the information regarding using a plate as a reference to monitor food proportions as well as using your hand to determine the portion sizes of specific foods. Regarding the specificity of the information, the fact that the educational training used data that were not specific to gymnasts could have resulted in having a lower impact on the gymnasts. The recommendations made by some of the gymnasts and the coach may be helpful in this regard. They mentioned the need to individualize the educational program using data from the same athletes to engage each subject more. Also, they mentioned the need for a follow-up of their diet and for incorporating feedback that is applicable in the daily life of the gymnast. This approach will allow the gymnasts to combine theoretical knowledge with their ability to apply that knowledge.

A previous study carried out with volleyball players has shown the effectiveness of the combination of educational training and a follow-up with a dietician (Valliant, Pittman Emplaincourt, Kieckhaefer Wenzel, Garner, 2012). Several aspects must be considered. The volleyball sample's knowledge was not as high at the beginning of the process. Therefore, it is possible that the educational program must be adapted and involve more individualization. If possible, the involvement of a dietician is recommended. However, oftentimes, gymnastics clubs do not have the possibility to collaborate with a dietician. Another possibility for implementing this type of educational program in this population would be the use of online educational training or educational software that allows gymnasts to automatically receive feedback from a dietician. However, it is not known whether this approach will help to increase the gymnasts' knowledge and improve their habits. Some studies have shown that gymnasts are knowledgeable about nutrition and they use this knowledge to modify their diets and to try to achieve and maintain the physical standards of the sport (Boros, 2009; Cupisti et al., 2000; Karabudak et al., 2016). More studies are needed to assess the effect of other intervention approaches in elite gymnasts.

\section{Conclusions}

The educational intervention that combines theoretical and practical classes and provides the athletes with educational material did not change the gymnasts' knowledge about nutrition or weight management. The gymnasts' knowledge of nutrition and weight management before the intervention was high, given that they scored higher than $75 \%$ on a knowledge test. Future studies are needed to determine what approach must be followed to effectively provide educational training to elite gymnasts. The gymnasts and the coach expressed the need for individualized training adapted to each gymnast's needs and for incorporating a follow-up that provides feedback that is applicable in the gymnast's daily life.

\section{References}

Anderson, C., Petrie, T.A. (2012). Prevalence of disordered eating and pathogenic weight control behaviors among NCAA division I female collegiate gymnasts and swimmers. Research Quarterly for Exercise and Sport, 83 (1), 120-124.

Bean's, A. (2010). Sports nutrition for young athletes. London: A \& C Black Publishers Ltd.

Bonci, C.M., Bonci, L.J., Granger, L.R., Johnson, C.L., Malina, R.M., Milne, L.W., Ryann, R.R., Vanderbunt, E.M. (2008). National athletic trainers' association position statement: Preventing, detecting, and managing disordered eating in athletes. Journal of Athletic Training, 43, 80-108.

Boros, K. (2009). Dietary habits and physical self-concept of elite rhythmic gymnasts. Biomedical Human Kinetics, 1, 1-2. 
Bulger, S.M., Housner, L.D. (2007). Modified Delphi investigation of exercise science in physical education teacher education. Journal of Teaching in Physical Education, 26 (1), 57-80.

Burke, L.M., Slater, G., Broad, E.M., Haukka, J., Modulon, S., Hopkins, W.G. (2003). Eating patterns and meal frequency of elite Australian athletes. International Journal of Sport Nutrition and Exercise Metabolism, 13 (4), 521-538.

Coelho-Bortoleto, M.A., Bello, M.L., Almeida, C. (2007). Sport nutrition applied to artistic gymnastics: A systematization of the scientific production. 0 mondo da saude Sao Paulo, 31 (4), 521-529.

Coppola, S., Vastola, R., Scatigna, M., Fabiani, L. (2014). Training and health in gymnastics. 9th INSHS International Christmas Sport Scientific Conference, 4-6 December 2014. International Network of Sport and Health Science. Szombathely, Hungary.

Cupisti, A., D'Alessandro, C., Castrogiovanni, S., Barale, A., Morelli, E. (2000). Nutrition survey in elite rhythmic gymnasts. Journal Sports Medicine and Physical Fitness, 40 (4), 350-355.

D’Alessandro, C., Morelli, E., Evangelisti, I., Galetta, F., Franzoni, F., Lazzeri, D., Piazza, M., Cupisti, A. (2007). Profiling the diet and body composition of subelite adolescent rhythmic gymnasts. Pediatric Exercise Science, 19 (2), 215-227.

Deutz, R.C., Benardot, D., Martin, D.E., Cody, M.M. (2000). Relationship between energy deficits and body composition in elite female gymnasts and runners. Medicine and Science in Sports and Exercise, 32 (3), 659-668.

Djordjevic-Nikic, M., Moskovljevic, L. (2009). Uticaj sportskog treninga na rast i polni razvoj takmičarki u ritmičkoj gimnastici (The influence of sports training on the growth and pubertal development in female rhythmic gymnasts). Fizička kultura, 63 (1), 3-9.

Douda, H., Laparidis, K., Tokmakidis, S.P. (2010). Long-Term Training Induces Specific Adaptations on the Physique of Rhythmic Sports and Female Artistic Gymnasts. European Journal of Sport Science, 2 (3).

Douda, H.T., Toubekis, A.G., Avloniti, A.A., Tokmakidis, S.P. (2008). Physiological and anthropometric determinants of rhythmic gymnastics performance. International Journal of Sports Physiology and Performance, 3 (1), 41-54.

Elendu, I.C., Umeakuka, O.A. (2010). An exploratory study of weight-loss practices of gymnasts in Rivers State, Nigeria. Pakistan Journal of Nutrition, 9, 352-357.

Evans, J., Rich, E., Holroyd, R. (2004). Disordered eating and disordered schooling: What schools do to middle class girls. British Journal of Sociology of Education, 25 (2), 123-142.

Filaire, E., Lac, G. (2002). Nutritional status and the body composition of juvenile elite female gymnasts. Journal of Sports Medicine and Physical Fitness, 42 (1), 65-70.

Gomez-Campos, R., Camargo, C., Arruda, M., Cossio Bolaños, M.A. (2013). Crecimiento físico y estado nutricional de gimnastas rítmicas de élite. Nutrición Clínica y Dietética Hospitalaria, 33 (1), 31-37.

Halmi, K. (2009). Anorexia nervosa: An increasing problem in children and adolescents. Dialogues in Clinical Neuroscience, 11, 100-103.

Hergenroeder, A., Broun, B., Klish, W. (1997). Anthropometric measurements and estimating body compositions in ballet dancers. Medicine and Science in Sports and Exercise, 25, 145-150.

Jonnalagadda, S.S., Bernadot, D., Nelson, M. (1998). Energy and nutrient intakes of the United States national women's artistic gymnastics team. International Journal of Sport Nutrition, 8, 331-344.

Karabudak, E., Köksal, E., Ertaş, Y., Küçükerdönmez, Ö. (2016). Dietary intake of Turkish gymnast and non-gymnast children. Nutrition and Dietetics, 73 (2), 184-189.

Klentrou, P., Plyley, M. (2003). Onset of puberty, menstrual frequency, and body fat in elite rhythmic gymnasts compared with normal controls. British Journal of Sports Medicine, 37, 490-494.

Lazarević, L.V., Petrović, B., Damnjanović, K. (2012). Personality traits of young gifted rhythmic gymnasts. Physical Education and Sport, 10 (2), 115-126.

Michopoulou, E., Avloniti, A., Kambas, A., Leontsini, D., Michalopoulou, M. (2011). Elite premenarcheal rhythmic gymnasts demonstrate energy and dietary intake deficiencies during periods of intense training. Pediatric Exercise Science, 23, 560-572.

Nordin, S., Harris, G., Cumming, J. (2003). Disturbed eating in young, competitive gymnasts: Differences between three gymnastics disciplines. European Journal of Sport Science, 3 (5), 1-14.

Soric, M., Misigoj-Durakovic, M., Pedisic, Z. (2008). Dietary intake and body composition of prepubescent female aesthetic athletes. International Journal of Sport Nutrition and Exercise Metabolism, 18, 343-354.

Stewart, C., Schiavon, L.M., Bellotto, M.L. (2015) Knowledge, nutrition and coaching pedagogy: A perspective from female Brazilian Olympic gymnasts. Sport, Education and Society. 
Sundgot-Borgen, J. (1994). Risk and trigger factors for the development of eating disorders in female elite athletes. Medicine and Science in Sports and Exercise, 26 (4), 414-419.

Sundgot-Borgen, J. (1996). Eating disorders, energy intake, training volume, and menstrual function in high-level modern rhythmic gymnasts. International Journal of Sport Nutrition, 6, 100-109.

Sundgot-Borgen, J., Torstveit, M.K. (2004). Prevalence of eating disorders in elite athletes is higher than in the general population. Clinical Journal of Sport Medicine, 14 (1), 25-32.

Tan, J.O., Calitri, R., Bloodworth, A., McNamee, M.J. (2016). Understanding eating disorders in elite gymnastics: Ethical and conceptual challenges. Clinical Journal of Sport Medicine, 35 (2), 275-92.

Valliant, M.W., Pittman Emplaincourt, H., Kieckhaefer Wenzel, R., Garner, B.H. (2012). Nutrition education by a registered dietitian improves dietary intake and nutrition knowledge of a NCAA female volleyball team. Nutrients, 4 (6), 506-516.

Visiedo, A., Frideres, J.E., Palao, J.M. (2017). Design, validation and reliability of survey to measure the knowledge in nutrition, weight control and its risk. Central European Journal of Sport Sciences and Medicine, 19 (4), 39-51.

Cite this article aS: Visiedo, A., Frideres, J.E., Palao, J.M. (2021). Effect of Educational Training on Nutrition and Weight Management in Elite Spanish Gymnasts. Central European Journal of Sport Sciences and Medicine, 1 (33), 53-59. DOI: 10.18276/cej.2021.1-05. 